\title{
Using models of energy consumption from influencing factors to assess the current state and energy efficiency forecasting
}

\author{
Deniz Moroz ${ }^{1, *}$, Nadzeya Hruntovich ${ }^{2}$, Aliaksei Kapanski ${ }^{2}$, Yauhen Shenets ${ }^{3}$, Mikhail Malashanka ${ }^{4}$, and Elena Gracheva ${ }^{5}$ \\ ${ }^{1}$ State Enterprise "Research Institute Belgiprotopgaz", Domashevskij lane,11a, Minsk, Republic of Belarus \\ ${ }^{2}$ Sukhoi State Technical University of Gomel, Prospect Octiabria, 48, 246746, Gomel, Republic of Belarus \\ ${ }^{3}$ Public corporation "Gazprom transgaz Belarus" Nekrasova 9, Minsk, Republic of Belarus \\ ${ }^{4}$ Energy Efficiency Department of the State Committee for Standardization of the Republic of Belarus, Minsk, \\ Svobody sq. 17, 220030, Republic of Belarus \\ ${ }^{5}$ Kazan State Power Engineering University, str. Krasnoselskaya, 51, 420066, Kazan, Russia
}

\begin{abstract}
A complex of tasks that can be solved using mathematical models of the dependence of consumed energy resources on influencing factors are considered in the article. The main type of model for industrial consumers with a simple relationship between energy and technology, is the one-factor model "consumed energy resource-volume of output". For industrial consumers with a complex relationship between energy and technology, the mathematical model of the dependence of energy resources on technology is determined by several factors. Methods for assessing the current state of energy efficiency, as well as predicting it for the future in the context of the introduction of energy saving measures and changes in the production program were proposed.
\end{abstract}

\section{Introduction}

The task of developing a methodological base in terms of assessing the current state and predicting energy efficiency indicators for industrial consumers actively engaged in the modernization and implementation of innovative technologies is currently important. The International Energy Agency is obliged to conduct fundamental and applied research in the field of energy conservation and high efficiency technologies. The International Energy Agent emphasizes the need to improve the methodology for energy surveys of FER (fuel and energy resources) consumers. The basis for the development of a methodological base for assessing the state and predicting performance indicators can be one-, multifactor models associated with energy consumption or even with total energy costs $[1,2,3]$.

\section{Research results}

There is a positive experience of using mathematical models of power consumption for oil transportation enterprises, water supply and sewerage facilities, flat glass enterprises, chemical fiber enterprises and a number of enterprises in other industries $[1,4,5]$. For example, a mathematical model for oil transportation enterprises is presented in the form of a three-factor additive regression equation for a selected cargo turnover interval, where each of the factors is a multiparameter characteristic of a subsystem participating in the formation of power consumption of the technological system as a whole. These factors include: oil cargo turnover; oil viscosity; equivalent diameter of the pipeline. For oil transportation enterprises, using the model, a method for assessing energy savings from energy-saving measures in the technological process of oil transportation enterprises was developed: using the elasticity coefficients of the additive regression model of electricity consumption, the impact of each factor on energy savings was assessed, the change in the state of the oil pipeline system was taken into account when assessing savings energy [6].

It should be noted that oil transportation, water supply and sewerage systems are complex technical systems consisting of several subsystems closely interconnected and having a significant impact on the power consumption of the system as a whole. Such technical systems can be classified as consumers of fuel and energy resources (FER) with a complex relationship between energy and technology. The functioning of these systems is determined by the nature of the relationships between its subsystems, as well as external and internal "disturbing" influences. Such technological system as energy efficiency management objects is not a simple sum of its constituent structures, but has its own individual properties and development patterns, different from the patterns of functioning of individual subsystems and elements included in the system $[7,8,9]$. It became possible to take these features into consideration through the development of regression models describing the consumption of fuel and energy resources and the creation on their basis of a system for forecasting, rationing, assessing the economy of fuel and

\footnotetext{
* Corresponding author: frostden@ list.ru
} 
energy resources, assessing energy efficiency indicators, which ultimately makes possible to increase the efficiency of energy management $[10,11,12,13]$.

For the majority of consumers of fuel and energy resources, the technological subsystem can be represented by subsystems of a lower level: raw materials, technological equipment $[14,15,16,17]$. Since the qualitative and quantitative indicators of technological equipment are relatively stable over relatively short periods of time (a year or two), and the raw materials used also have relatively stable characteristics, the model for assessing the current state for predicting energy efficiency indicators will represent the dependence of energy consumption only on the volume of production. The relationship between energy and technology will be simple. The works, previously published, showed that in the most general form the energy characteristic can be represented by the equation $[1,6]$ :

$$
W=w_{s p} P+W_{\text {const }},
$$

where $W$ - power consumption for a given period of time, $\mathrm{kWh} ; w_{s p}-$ specific power consumption per unit of production, $\mathrm{kWh} /$ unit of production; $P$ - volume of production, unit of production; $W_{\text {const }}-$ the constant part of the electricity consumption, basically, independent of the load, $\mathrm{kWh}$.

\section{Energy efficiency assessment through the example of water supply and sewerage enterprises}

It is the presence of a conditionally constant component of electricity consumption $W_{\text {const }}$ in the factory, workshop power consumption that led to the fact that, in general, the dependence of the plant-wide specific power consumption $w_{s p}$ on the volume of production has a hyperbolic dependence (Fig. 2 a). Finding the regression coefficient $w_{s p}$ with the known daily statistical data of electricity consumption and the corresponding volume of production is determined by the least squares method. The calculation mechanism is discussed in detail in various articles [1, 10]. However, in most cases, the accumulation of daily statistics at enterprises is difficult, while monthly statistics are mandatory for accounting. In view of the fact that the number of days in a month is not a constant value, an approach was proposed that makes it possible to adjust the cost of electricity taking into account the actual number of days in the billing period with quarterly or annual planning of electricity consumption. Let's consider the proposed algorithm using the example of a water supply system of one of the water utilities of the Republic of Belarus, for which an additive form of the model was established that had passed all the relevant statistical checks [10]:

$$
W=w_{s p} Q_{w}+a t_{\text {air }}+\mathrm{W}_{\text {const }}^{\text {month }},
$$

where $Q_{w}$ - planned volumes of water production, $\mathrm{m}^{3}$; $\mathrm{kWh} ; \quad a$-regression coefficient before the outdoor temperature factor, $\mathrm{kWh} /{ }^{\circ} \mathrm{C} ; t_{\text {air }}$-average outside air temperature during the forecasting period, ${ }^{\circ} \mathrm{C} ; \mathrm{W}_{\text {const }}^{\text {month }}$ the free term of the regression characterizing the monthly conditionally constant costs that do not depend on the factors forming the power consumption, $\mathrm{kWh}$.

In addition, for large water supply systems, the influence of the outside air temperature on the formation of total and specific EE costs is observed. The significance of the temperature factor is associated, firstly, with a change in the operating modes of general production plants, and secondly, with an increase in temperature, pressure losses in pipelines decrease depending on the kinematic viscosity of the liquid. However, an increase in temperature does not always lead to a decrease in power consumption. The study of the water supply system in Rechitsa city (the Republic of Belarus) revealed the opposite effect. An increase in the outside air temperature by $1{ }^{\circ} \mathrm{C}$ led to an increase in electricity consumption by $16.6 \mathrm{kWh}$. The increase in electricity consumption on the warmest days was caused by the inclusion of additional pumping units and drinking water purification devices due to an increase in water consumption, which covered the effect of a decrease in general production and technological energy efficiency costs.

For quarterly or annual forecasting of electricity consumption, $\mathrm{kWh}$, the monthly model of formula (2) is converted to the form:

$$
W=w_{s p} Q_{w}+\left(a t_{\text {air }}+\mathrm{W}_{\text {const }}^{\text {month }}\right) \cdot N_{\text {month }}^{\prime},
$$

where $N_{\text {month }}^{\prime}$ - the number of months in the forecasting period given to comparable conditions, which is determined by the formula:

$$
N_{\text {month }}^{\prime}=\frac{12 \cdot N_{\text {day }}}{N_{\text {year }}}
$$

where $N_{d a y}$ - the number of days in the forecasting period; $N_{\text {year }}-$ the number of days in a calendar yea.

For example, for a quarterly forecast of electricity consumption with $N_{d a y}=90$ days included in the calendar year with $N_{\text {year }}=365$ days, the given number of months will be $N_{\text {month }}^{\prime}=12 \cdot 90 / 365=2.96$ months.

From the analysis of the above ratios, it should be concluded that the monthly model of electricity consumption is adapted by adjusting the number of months in the forecast year [18, 19 20]. However, if the statistical database includes periods with a different number of calendar days (leap year), then it is advisable to bring the monthly view of the model to the daily sampling rate at the stage of data processing. Bringing the models to a unified form allows not only avoiding errors in averaging calendar days, but also using a 


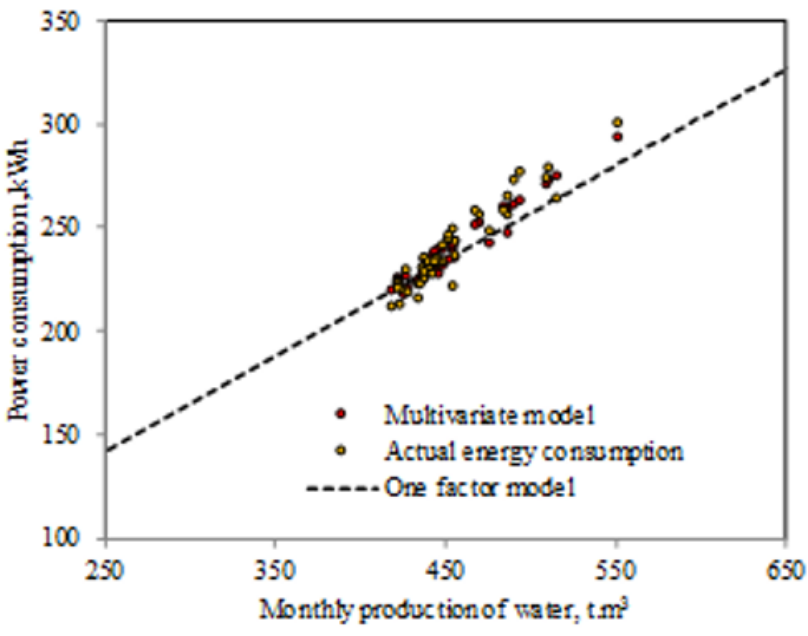

a)

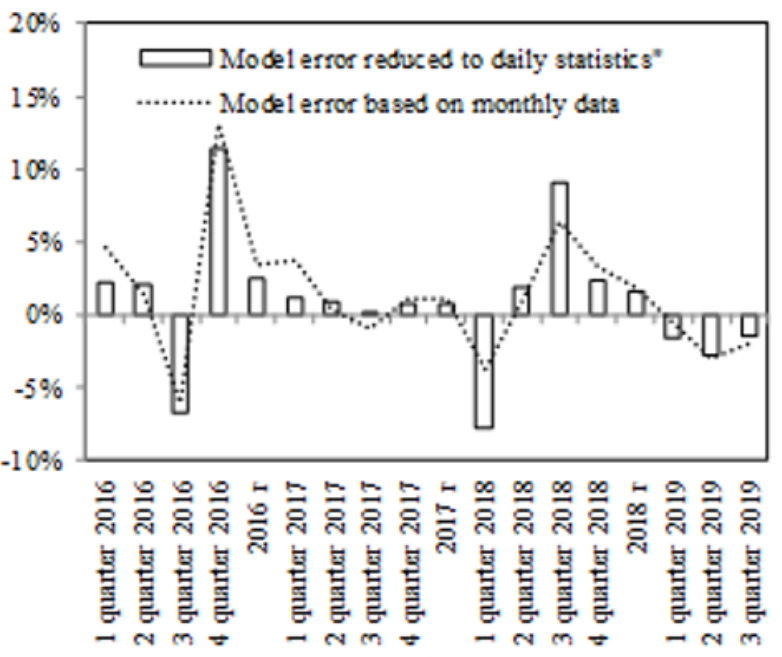

b)

Fig. 1. Model of electricity consumption in the water supply system (a) and assessment of the forecasting quality with different options for bringing statistical data (b)

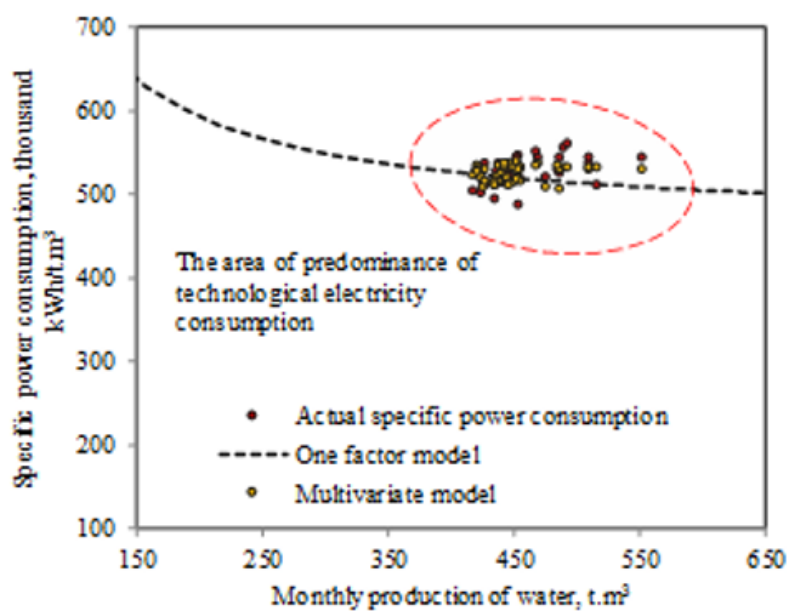

a)

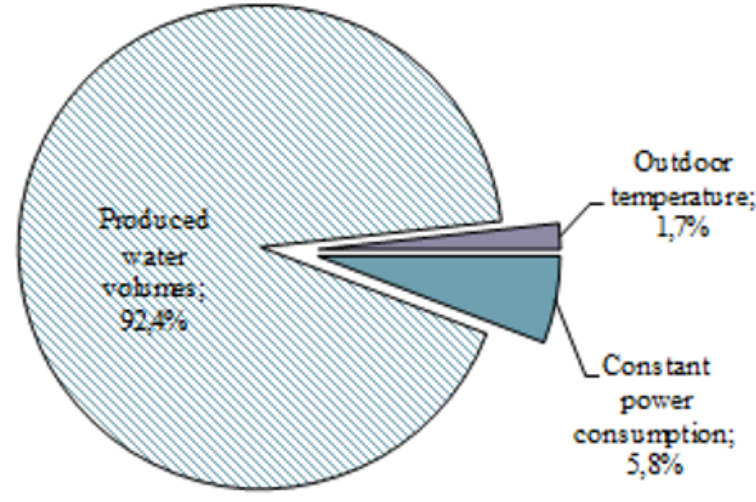

b)

Fig. 2. Model of electricity consumption in the water supply system (a) and assessment of the forecasting quality with different options for bringing statistical data (b)

unified form for comparing the energy efficiency of the studied enterprises:

$$
x_{\text {ave }}=\frac{1}{T} X,
$$

where $X$ - the factor values with the original sampling period; $T$-sampling period of factor $X$, days; $x_{\text {ave }}-$ reduced daily averaging of factor $X$.

A quantitative assessment of the simulation results at various levels of discretization of statistical data made it possible to establish a decrease in the mean-square forecasting error by $0.53 \%$ due to the transition to a daily form at the stage of processing statistical data. Fig. 1 shows a model of electricity consumption in a water supply system (a) and an assessment of the forecasting quality with various options for bringing statistical data (b).
For the investigated water utility, the composition of the specific consumption of electricity is mainly formed by technological consumption of electricity, i.e. those costs that are directly related to the transport of water, as a result of which the characteristic in the working area takes on a flatter form and, accordingly, less sensitivity to changes in production volumes (Fig. 2).

Thus, the use of the proposed method for modeling electricity consumption allows:

1. To assess the current state of the energy efficiency of production, for example, for a water utility, the indicator of the sensitivity of changes in the specific consumption of electricity when changing the volume of water produced was used, which was $7.5 \%$ and was determined by the formula [10]:

$$
k=\left|\frac{w_{s p} \cdot Q_{w}}{w_{s p} \cdot Q_{w}+\left(a \cdot t_{\text {air }}+\mathrm{W}_{\text {const }}^{\text {month }}\right) N_{\text {month }}^{\prime}}-1\right| .
$$


Table 1. Readings of energy metering devices and data of electrical balance.

\begin{tabular}{|l|c|c|c|}
\hline Entitlement & Unit of measurement & Metered values & Calculation data \\
\hline Annual electric power consumption & $\mathrm{kWh}$ & 152000 & - \\
\hline Technological electric power consumption & $\mathrm{kWh}$ & 60800 & - \\
\hline Conditional-constant flow & $\mathrm{kWh}$ & 91200 & - \\
\hline Output manufactured & thousand units of products & 450 & - \\
\hline Technological specific energy consumption & $\begin{array}{c}\mathrm{kWh} / \text { thousand units of } \\
\text { products }\end{array}$ & - & 135.11 \\
\hline Total production specific power consumption & $\begin{array}{c}\mathrm{kWh} / \text { thousand units of } \\
\text { products }\end{array}$ & - & 337.78 \\
\hline
\end{tabular}

Table 2. Calculation of unit costs of energy efficiency and assessment of the EEF regulation ability for garment production.

\begin{tabular}{|c|c|c|c|c|}
\hline $\begin{array}{c}\text { Production } \\
\text { volume, } \boldsymbol{P}, \\
\text { thousand units of } \\
\text { products }\end{array}$ & $\begin{array}{c}\text { Specific power } \\
\text { consumption, } \boldsymbol{w}_{\boldsymbol{s} \boldsymbol{p} .} \\
\mathbf{k W h} \text { / thousand } \\
\text { units of products }\end{array}$ & $\begin{array}{c}\text { Energy efficiency } \\
\text { horizontal adjustment } \\
\text { capacity, \% }\end{array}$ & $\begin{array}{c}\text { Predicted specific electric } \\
\text { power consumption after the } \\
\text { implementation of energy } \\
\text { saving measures, } \boldsymbol{w}_{\boldsymbol{s} p} \text {. } \mathbf{k W h} \text { / } \\
\text { thousand units of products }\end{array}$ & $\begin{array}{c}\text { The effect of the } \\
\text { implementation of } \\
\text { energy saving } \\
\text { measures, \% }\end{array}$ \\
\hline $\mathrm{A}$ & $\mathrm{B}$ & $\mathrm{C}$ & $\mathrm{D}$ & $\mathrm{F}$ \\
\hline 315 & 424.5 & basis & 362.2 & -14.7 \\
\hline 360 & 388.3 & -8.5 & 334.4 & -13.9 \\
\hline 405 & 360.2 & -15.2 & 295.6 & -13.1 \\
\hline 450 & 337.7 & -20.5 & 281.4 & -12.5 \\
\hline 495 & 319.2 & -24.8 & 269.6 & -11.8 \\
\hline 540 & 303.9 & -28.4 & 259.7 & -11.3 \\
\hline 585 & 290.9 & -31.5 & & -10.7 \\
\hline
\end{tabular}

2. Assess the regulatory capacity for energy efficiency of production.

3. To carry out a forecast of the total and specific consumption of energy resources in the context of changes in the volume of production and the implementation of energy saving measures.

4. Assess the effect of the implemented energy saving measures in the context of a changing production program. The priority of the choice of energy-saving areas lies in the maximum effect of the measures being introduced, i.e. maximum reduction in specific power consumption or its sensitivity to changes in production volumes. With an insignificant effect of the volume of production on the change in the specific consumption of electricity, i.e. at a value of $\mathrm{k}$ from 0 to 0.5 where the structure of power consumption is formed mostly by technological power consumption. In this regard, energy saving measures should be aimed primarily at reducing the technological costs of electricity, i.e. to improve energy efficiency, for example, pumping equipment. Otherwise, there should be measures taken to reduce the fixed costs of electricity in the overall structure of electricity consumption (Fig. 2 b).

\section{Assessment of energy efficiency of garment production}

Let's consider another example of using mathematical modeling to assess the energy efficiency of a garment industry. On the basis of the electrical balance, the structure of power consumption was formed with a volume of 450 thousand units of production (Table 1).
Then the equation describing the change in the specific consumption of electricity from the volume of production will have the following form:

$$
w_{s p}=w_{s p . t}+\frac{W_{c o n s t}}{P}=135.11+\frac{91200}{P},
$$

where $w_{\text {sp.t }}$ - the technological specific power consumption, $\mathrm{kWh} /$ thousand units of products.

Table 2 (columns A, B) shows the calculated values of plant-wide specific electricity consumption, taking into account the possible annual range of production $P_{\min }=315$ thousand units of products and $P_{\max }=585$ thousand units of products. From Tabl. 2 it can be seen that the minimum value of the specific power consumption $w_{s p \text { min }}$ is $290.9 \mathrm{kWh} /$ thousand units of products. The maximum $w_{s p \text { max }}$ value corresponding to the minimum production volume is $424.5 \mathrm{kWh} \mathrm{/}$ thousand units of products.

\subsection{Assessment of the current state of energy efficiency in production}

The current state of energy efficiency is determined by the location of the point of the achieved value of the general production value of the specific electricity consumption on the graphical interpretation of the calculated values of the specific electricity consumption from the annual production volume relative to the values of the previous year. 


\subsection{Assessment of the regulatory capacity due to energy efficiency of production}

Energy efficiency adjusting ability is the ability of both individual structural elements and the entire technical system as a whole to change the specific and total costs of energy resources depending on the influencing factors. Distinguish between horizontal regulation capacity for energy efficiency (due to changes in the volume of production) and vertical regulation capacity (due to control of technological parameters and characteristics of raw materials) [6]. The potential for horizontal energy efficiency improvement relative to the minimum production volume is determined in accordance with the model:

$$
\Delta \mathrm{EEF}=\frac{w_{s p . i}-w_{s p \text { min }}}{w_{s p \text { min }}} 100 \%,
$$

where $w_{s p . i}$ - the value of the specific consumption of energy resources corresponding to the $\mathrm{i}$ volume of production; $w_{s p \text { min }}-$ the value of the specific consumption of energy resources corresponding to the minimum volume of production.

The main essence of horizontal regulation is that, with a change in the volume of production (increasing or decreasing the load of technological equipment), the operating point of the hyperbolic curve of dependence (7) shifts towards a decrease or increase. In Tabl. 2 (Column C) shows the calculation of the energy efficiency regulation capacity. As you can see from Tabl. 2 the maximum potential for reducing the specific power consumption for garment production is $-31.5 \%$.

\subsection{Forecast of the total and specific consumption of energy resources in the context of changes in the volume of production and the implementation of energy saving measures}

The forecast of the total and specific consumption of energy resources in the implementation of energy saving measures is made on the basis of adjusting the indicators of the existing model by the value of the expected effect from the implementation of energy saving measures. For example, for the initial model of the form (7), 21200 $\mathrm{kWh}$ of the annual effect of energy saving measures, which affect the conditionally constant component of power consumption, was subtracted from the conditionally constant power consumption of 91200 $\mathrm{kWh}$. As a result, the adjusted model took the following expression $w_{s p}=135.11+70000 / P$, which made it possible to calculate new values of specific electricity consumption (Tabl. 2, column D). A graphic interpretation of the model, adjusted for energy saving measures, is presented in Fig. 3. A decrease in the volume of production in some cases can completely compensate for the effect of energy saving measures.

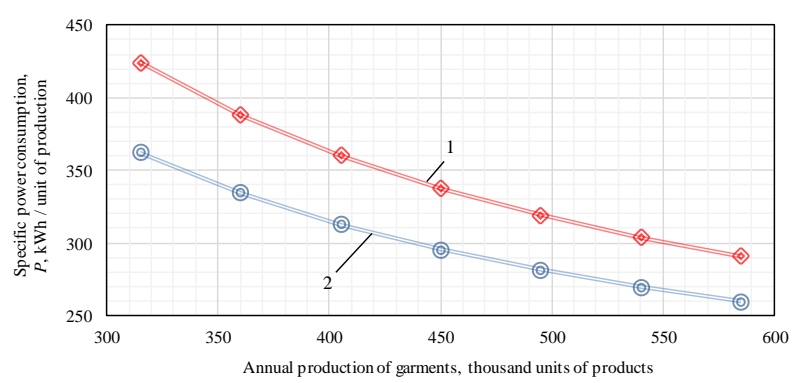

Fig. 3. Models of energy consumption from the output of garment production: 1 - initial model; 2 - a model adjusted when implementing energy saving measures.

\subsection{Assessment of the effect of energy saving measures in the context of a changing production program}

For an objective assessment of the effect of the implementation of energy saving measures, it is necessary to compare the unit costs before and after the implementation of energy saving measures corresponding to the same volume of production. It is impossible to compare the specific consumption of electricity for different volumes of production, since the overall change in the energy efficiency of a technical system consists of two components: changes in the volume of production and the effect of the implemented energy saving measures. In addition, the very effect of energy saving measures manifests itself differently for different volumes of production (Tabl. 2, F). The maximum effect from energy saving measures is $14.7 \%$, and the minimum value is $-10.7 \%$. The effect of measures affecting the conditionally constant consumption of energy is manifested to a greater extent with a decrease in the volume of production.

\section{Conclusions}

The industrial sector is one of the most difficult energy efficiency indicators to research.

The use of an analytical approach in assessing changes in specific electricity consumption leads to significant discrepancies between actual and calculated values and, ultimately, distorts the real state of the energy efficiency of the industrial sector.

The most important element in assessing the energy efficiency of production, ways to improve it, as well as the implementation of energy saving measures is mathematical modeling of energy processes. Taking into account the system properties of energy survey objects makes it possible to avoid errors in assessing the specific consumption of energy resources when implementing energy saving measures.

\section{References}

[1] N.V. Tokochakova, A.S. Fikov, Development of mathematical models of power consumption modes of industrial consumers on the example of oil pipeline transport enterprises, Vestn. G. state. tech. 
un-ta them. P.O. Sukhoi 1, 71-84 (2007) (in Russian)

[2] A. Harvey, S.J. Koopman, Forecasting hourly electricity demand using time-varying splines, Journal of the American Statistical Association 88, 424, 1228-1236 (1993)

[3] U. Kumar, V.K. Jain, Time series models (GreyMarkov, Grey Model with rolling mechanism and singular spectrum analysis) to forecast energy consumption in India, Energy 35, 4, 1709-1716 (2010)

[4] A.A. Kapansky, Energy Efficiency of the Technological Systems of Water Supply and Drainage and Methods of Its Evaluation, Izv. higher studies, institutions and energy, about the CIS, Energy 5, 436-451 (2016) (in Russian)

[5] D. Moroz, N. Hruntovich, N. Hruntovich, S. Jhukovets, A. Kapansky, L. Dolomanyak, The study of structural fields of daily gas consumption of the balance groups of the regional gas supply system, EDP Sciences, E3S Web of Conferences 178, 01066 (2020)

[6] N.V. Tokochakova, Energy efficiency management of industrial consumers based on the simulation of power consumption modes, Izv. higher. study. head and energetic. ed. CIS - Energy 3, 67-75 (2006) (in Russian)

[7] L. Melentiev, Selected works, Methodology of system researches in power engineering (Moscow, Nauka, 1995) 289

[8] O.V. Fedorov, Expeditious forecasting of power consumption, 2017 International Conference on Industrial Engineering, Applications and Manufacturing (ICIEAM), IEEE (2017)

[9] Y.I. Gracheva, A.N. Alimova, Calculating Methods and Comparative Analysis of Losses of Active and Electric Energy in Low Voltage Devices, International Ural Conference on Electrical Power Engineering (UralCon), 361-367 (2019)

[10] A.A. Kapansky, Management of energy efficiency of pipeline drainage systems based on multifactor modeling of power consumption modes, Agrotechnics and energy supply 1, 10, 51-63 (2016) (in Russian).

[11] V. Bianco, O. Manca, S. Nardini, Electricity consumption forecasting in Italy using linear regression models, Energy 34, 9, 1413-1421 (2009)

[12] S. Saab, E. Badr, G. Nasr, Univariate modeling and forecasting of energy consumption: the case of electricity in Lebanon, Energy 26, 1, 1-14 (2001)

[13] A.J. Conejo, et al., Day-ahead electricity price forecasting using the wavelet transform and ARIMA models, IEEE transactions on power systems 20, 2, 1035-1042 (2005)

[14] S. Kadoshin, T. Nishiyama, T. Ito, The trend in current and near future energy consumption from a statistical perspective, Applied Energy 67, 4, 407417 (2000)
[15] P.K. Narayan, R. Smyth, Electricity consumption, employment and real income in Australia evidence from multivariate Granger causality tests, Energy policy 33, 9, 1109-1116 (2005)

[16] N.V. Hruntovich, A.A. Kapanski, D. Baczynski, G.V. Vagapov, O.V. Fedorov, Optimization of a variable frequency drive pump working on a water tower, EDP Sciences, E3S Web of Conferences 124, 05060 (2019)

[17] Y.I. Gracheva, O.V. Naumov, Estimation of Power Losses in Electric Devices of the Electrotechnical Complex, International Conference on Industrial Engineering, Applications and Manufacturing (ICIEAM), 6 (2019)

[18] A. Kapanski, N. Hruntovich, S. Bakhur, L. Markaryants, L. Dolomanyak, Optimize the cost of paying for electricity in the water supply system by using accumulating tanks, EDP Sciences, E3S Web of Conferences 178, 01065 (2020)

[19] E. Erdogdu, Electricity demand analysis using cointegration and ARIMA modelling: A case study of Turkey, Energy policy 35, 2, 1129-1146 (2007)

[20] R. Haas, L. Schipper, Residential energy demand in OECD-countries and the role of irreversible efficiency improvements, Energy economics 20, 4, 421-442 (1998)

[21] Balzamov, I.G. Akhmetova, E.Y. Balzamova, G.I. Oykina, V.V. Bronsrkaya, Options for organizing own sources of energy supply at the facilities of generating companies based on steam screw machines, Journal of Physics: Conference Series 1399(5), 055018 (2019)

[22] A. Kulachinskaya, I.G. Akhmetova, V.Y. Kulkova, S.B. Ilyashenko, The challenge of the energy sector of russia during the 2020 covid-19 pandemic through the example of the republic of tatarstan: Discussion on the change of open innovation in the energy sector, Journal of Open Innovation: Technology, Market, and Complexity 6(3), 60 (2020)

[23] N. Ketoeva, N. Soldatova, N. Rebrikova, and S. Ilyashenko, Russian Hydropower Sector and its Human Resources Under Digitization Conditions,IOP Conference Series: Materials Science and Engineering, 497(1), 012121 (2019) doi:10.1088/1757-899X/497/1/012121 